\title{
Contrast-enhanced ultrasound of benign and malignant liver lesions in children
}

\author{
Cheng Fang ${ }^{1}$ (D) - Sudha A. Anupindi ${ }^{2}$. Susan J. Back ${ }^{2}$. Doris Franke ${ }^{3} \cdot$ Thomas G. Green $^{4} \cdot$ Zoltan Harkanyi $^{5}$. \\ Jörg Jüngert ${ }^{6}$. Jeannie K. Kwon ${ }^{7} \cdot$ Harriet J. Paltiel $^{8}$ • Judy H. Squires ${ }^{9} \cdot$ Vassil N. Zefov ${ }^{10} \cdot$ M. Beth McCarville ${ }^{11}$
}

Received: 28 September 2020 / Revised: 17 November 2020 / Accepted: 14 January 2021 / Published online: 12 May 2021

(C) The Author(s) 2021

\begin{abstract}
Contrast-enhanced ultrasound (CEUS) is increasingly being used in children. One of the most common referrals for CEUS performance is characterization of indeterminate focal liver lesions and follow-up of known liver lesions. In this setting, CEUS is performed with intravenous administration of ultrasound contrast agents (UCAs). When injected into a vein, UCA microbubbles remain confined within the vascular network until they dissipate. Therefore, visualization of UCA within the tissues and lesions corresponds to true blood flow. CEUS enables continuous, real-time observation of the enhancement pattern of a focal liver lesion, allowing in most cases for a definite diagnosis and obviating the need for further cross-sectional imaging or other interventional procedures. The recent approval of Lumason (Bracco Diagnostics, Monroe Township, NJ) for pediatric liver CEUS applications has spurred the widespread use of CEUS. In this review article we describe the role of CEUS in pediatric liver applications, focusing on the examination technique and interpretation of main imaging findings of the most commonly encountered benign and malignant focal liver lesions. We also compare the diagnostic performance of CEUS with other imaging modalities for accurate characterization of focal liver lesions.
\end{abstract}

Keywords Benign · Children · Contrast-enhanced ultrasound $\cdot$ Lesion $\cdot$ Liver $\cdot$ Malignant $\cdot$ Ultrasound $\cdot$ Ultrasound contrast agents

\section{Introduction}

Liver applications of contrast-enhanced ultrasound (CEUS) are increasingly reported in children. Focal liver lesions can be encountered either incidentally in asymptomatic children during routine abdominal imaging examinations (usually by US), in staging or follow-up scans of children with cancer, or in the

Cheng Fang

chengfang@nhs.net

1 Department of Radiology, King's College Hospital, Denmark Hill, London SE5 9RS, UK

2 Department of Radiology, Perelman School of Medicine, Children's Hospital of Philadelphia, University of Pennsylvania, Philadelphia, PA, USA

3 Department of Pediatric Kidney, Liver and Metabolic Diseases, Hannover Medical School, Hannover, Germany

4 Department of Radiology, Crouse Hospital, Syracuse, NY, USA

5 Department of Radiology, Heim Pál National Pediatric Institute, Budapest, Hungary setting of surveillance programs for chronic liver disease or other conditions that predispose to malignancy (e.g., overgrowth syndromes). Common benign solid liver lesions in the pediatric population include infantile and congenital hemangiomas and focal nodular hyperplasia, whereas hepatic adenoma and regenerative nodular hyperplasia occur infrequently [1]. Occasionally, pseudo-lesions such as focal fat sparing or deposition mimic liver

6 Department of Pediatrics, Friedrich-Alexander University ErlangenNürnberg, Erlangen, Germany

7 Department of Radiology, University of Texas Southwestern Medical Center, Dallas, TX, USA

8 Department of Radiology, Harvard Medical School, Boston Children's Hospital, Boston, MA, USA

9 Department of Radiology, Children's Hospital of Pittsburgh, University of Pittsburgh Medical Center, Pittsburgh, PA, USA

10 Department of Radiology, Dubai Health Authority, Latifa Women and Children Hospital, Dubai, UAE

11 Department of Diagnostic Imaging, St. Jude Children's Research Hospital, Memphis, TN, USA 
lesions and warrant further investigation. The most common primary malignant tumor among children younger than 5 years is hepatoblastoma, and among those $15-19$ years old is hepatocellular carcinoma $[2,3]$.

Although the first-line imaging modality used for the detecting focal liver lesions is usually gray-scale US coupled with color/power Doppler techniques, its accuracy in characterizing the nature of a lesion is limited because of the nonspecific echo pattern of several lesions (predominantly small or deeply located lesions). Accuracy of Doppler US is also affected by artifacts (e.g., respiratory or cardiac motion artifacts, or shadowing from bowel gas or ribs) and technical limitations (e.g., inappropriate color scale settings). In most cases, US is followed by contrast-enhanced cross-sectional imaging, CT or MRI, the latter being preferable in pediatric patients for complete assessment of focal liver lesions.

Contrast-enhanced ultrasound (CEUS) is increasingly integrated into imaging algorithms for detecting and characterizing focal liver lesions. CEUS is particularly well-suited for the pediatric population because it is free of ionizing radiation, does not require sedation, lacks toxicity (renal, hepatic and cardiac) and can be performed in the presence of caregivers or even at the bedside. Performing CEUS simultaneously with the initial unenhanced US allows in most cases a definitive diagnosis and complete assessment of a lesion. This is particularly important because it alleviates the anxiety of children and families and facilitates the workflow in busy radiology departments.

Three currently available ultrasound contrast agents (UCAs) have been used for liver imaging in children: SonoVue (Bracco Imaging SpA, Milan, Italy), which is marketed as Lumason (Bracco Diagnostics, Monroe Township, NJ) in the United States; Optison (GE Healthcare, Princeton, NJ); and Definity (Lantheus, North Billerica, MA). In April 2016, the United States Food and Drug Administration (FDA) approved Lumason for intravenous liver applications in children. Currently, all other UCAs that are used are off-label for liver investigations in children.

Numerous CEUS studies conducted in adults and a growing number of CEUS studies in children have demonstrated a high safety profile for the intravenous use of UCAs [4-21]. In 2006, the largest prospective multicenter CEUS study, comprising 231,888 adults, reported an incidence of $0.13 \%$ for all adverse reactions and $0.01 \%$ for serious adverse reactions with UCA administration [22]. This is lower than what has been reported with iodine-based contrast media, for which overall acute allergic-like reaction frequency ranges from $0.18 \%$ to $0.46 \%$ in people who receive low-osmolality contrast media [23-27]. The allergic-like adverse reactions for gadolinium range $0.004 \%$ to $0.70 \%$, with the added risks of nephrogenic systemic fibrosis and tissue deposition [28-32].

The reported indications of CEUS for liver imaging in children include detection and characterization of indeterminate focal liver lesions. These lesions are either discovered incidentally or during surveillance imaging examinations, usually by US. However, CEUS can also be used as an adjunct or problem-solving tool in cases when MRI or CT are inconclusive or technically limited (e.g., when there are motion artifacts). In addition, CEUS has been used in the follow-up of known liver lesions that are either treated conservatively or have undergone interventional procedures (e.g., post chemotherapy or ablation) [33-35]. Other CEUS applications for liver imaging include trauma, post-liver transplantation, and interventional procedures. These are covered in detail in other articles in this supplement [36-38].

In this article, we discuss the role of CEUS in the characterization of focal liver lesions in children. We review the CEUS examination technique and the typical imaging features of the most common benign and malignant pediatric liver lesions. We also discuss the diagnostic performance of CEUS compared to that of other imaging modalities.

\section{Contrast-enhanced ultrasound examination technique}

\section{Patient preparation}

No sedation, general anesthesia or prior blood tests are required. Where available and when needed, a child life specialist might facilitate the study by helping the child to remain calm and cooperate with the examination.

\section{Ultrasound contrast agent dose}

The FDA-approved dose of Lumason for pediatric liver applications is $0.03 \mathrm{~mL} / \mathrm{kg}$, up to a maximum of $2.4 \mathrm{~mL}$ per single bolus dose. This dose can be given twice during an examination, if needed. Variable doses of SonoVue for liver imaging in the pediatric population have been published. These doses were either adjusted based on the child's age and body weight or were arbitrarily selected. Centers have employed a range of approaches to dose calculation. One center uses an age-based approach to doses of SonoVue, so that children younger than 6 years receive $0.6 \mathrm{~mL}, 6-12$ years $1.2 \mathrm{~mL}$ and older than 12 years $2.4 \mathrm{~mL}[7,8]$. Another center uses a different agebased approach so that children receive $0.1 \mathrm{~mL}$ of SonoVue per each year of age [17]. A third center uses a weight-based dose so that children weighing up to $24 \mathrm{~kg}$ receive $0.1 \mathrm{~mL} / \mathrm{kg}$, and those weighing more than $24 \mathrm{~kg}$ receive $2.4 \mathrm{~mL}$ [13]. Other centers use doses ranging from $0.1 \mathrm{~mL}$ to $4.8 \mathrm{~mL}[6$, 9-12] (Table 1; [6-9, 12, 13, 15, 21, 39]).

Optison has been used for pediatric abdominal applications of intravenous (IV) CEUS under an FDA-approved investigational new drug application. In the preliminary safety and feasibility part of the study, the selected dose of Optison was 
Table 1 Original research, pediatric exclusive contrast-enhanced ultrasound (CEUS) studies of focal liver lesions using SonoVue/Lumason

\begin{tabular}{|c|c|c|}
\hline Reference & Ultrasound contrast agent dose & CEUS exams for focal liver lesions $(n)^{\mathrm{a}}$ \\
\hline El-Ali 2020 [21] & $0.03 \mathrm{~mL} / \mathrm{kg}$ & 10 \\
\hline Fang 2019 [7] & $<1$ y: $0.6 \mathrm{~mL} ; \geq 1$ y: $1.2-2.4 \mathrm{~mL}$ & 30 \\
\hline Yusuf 2017 [8] & $<6$ y: $0.6 \mathrm{~mL} ; 6-12$ y: $1.2 \mathrm{~mL} ; \geq 12$ y: $2.4 \mathrm{~mL}$ & 147 \\
\hline Torres 2017 [13] & $0.1 \mathrm{~mL} / \mathrm{kg}$ (maximum $2.4 \mathrm{~mL}$ ) & $\begin{array}{l}\text { Native liver: } 92 \\
\text { Transplant liver:17 }\end{array}$ \\
\hline Knieling 2016 [15] & $<20 \mathrm{~kg}: 0.4 \pm 0.3 \mathrm{~mL} ;>20 \mathrm{~kg}: 1.0 \pm 0.4 \mathrm{~mL}$ & $41^{\mathrm{c}}$ \\
\hline Pschierer 2015 [12] & $0.5-3 \mathrm{~mL}$ & 49 \\
\hline Piskunowicz $2015[6]^{\mathrm{b}}$ & $0.1-1.8 \mathrm{~mL}$ & $48^{\mathrm{d}}$ \\
\hline Jacob $2013[9]$ & $1.2-2.4 \mathrm{~mL}$ & 44 \\
\hline Stenzel 2013 [39] & $0.1 \mathrm{~mL} /$ year of age & $14^{\mathrm{e}}$ \\
\hline
\end{tabular}

$y$ years

${ }^{\text {a }}$ While some studies included information about CEUS performed to assess non-focal lesions (e.g., portal vein or biliary assessment), only the information about focal liver lesions is summarized in this table

${ }^{\mathrm{b}}$ This study was prospective; all other studies were retrospective

${ }^{\mathrm{c}}$ Study included a total of 55 CEUS examinations; 41/55 were performed for focal liver lesions

${ }^{d}$ The study included a total of 161 CEUS examinations; 48/161 were performed for focal liver lesions

e The study included a total of 39 CEUS examinations; 14/39 were performed for focal liver lesions

initially based on body surface area, beginning at a very low dose of $0.125 \mathrm{~mL} / \mathrm{m}^{2}$ and escalating in $0.075 \mathrm{~mL} / \mathrm{m}^{2}$ increments to a maximum of $0.350 \mathrm{~mL} / \mathrm{m}^{2}$ [35]. Later, dosing of this agent was changed to a weight-based approach, such that children $<20 \mathrm{~kg}$ received $0.3 \mathrm{~mL}$ and those $\geq 20 \mathrm{~kg}$ received $0.5 \mathrm{~mL}$ of Optison [34]. Definity has been used in a few children for IV CEUS in abdominal applications, but no specific dosing data have been reported [34].

It is generally accepted that the dose can be adjusted according to the sensitivity of the US machine contrast software and transducer frequency because higher-frequency transducers require more UCA [40].

\section{Pre-contrast scan}

First, a baseline US scan is performed. In this scan the operator should determine the position of the child and the sonographic window that will allow an optimal view of the focal liver lesion at all times.

\section{Post-contrast scan}

The CEUS examination should be performed using contrastspecific low mechanical index imaging (i.e. <0.3) [41]. For the operator to constantly monitor the lesion throughout the examination, a dual screen with simultaneous display of the reference gray-scale US image alongside the contrastenhanced image is preferred, with or without simultaneous caliper display on both screens.

Contrast-enhanced US liver imaging should be performed with a curved-array transducer at a frequency of 3-10 MHz for infants and small children, whereas lower-frequency transducers of 1-5 MHz can be used in older or obese children to maximize contrast signals. Higher-frequency linear transducers (e.g., 2$9 \mathrm{MHz}$ ) can be used for small superficial liver lesions.

The child should be in a comfortable position, and scanned during free, shallow breathing. If the child is able, breath holds can be helpful to visualize lesions near the liver dome or beneath the ribs. The examination requires two people, one to scan and one to administer the contrast agent. When optimal visualization of the target lesion is established, the UCA is given and then the IV tubing is flushed with $3-10 \mathrm{~mL}$ of normal saline $(0.9 \%)$, pushing the residual contrast agent into circulation.

For the IV, the cannula is usually 24-gauge or larger and is placed in the antecubital fossa. However, smaller or more peripherally inserted cannulas can also be used, particularly in infants and small children, if this IV access is the only one available. A central line can be used if a peripheral one is not available.

\section{Interpretation of imaging findings}

When interpreting the enhancement features of a focal liver lesion, the examiner should have in mind the basic principles described in the following sections.

\section{Ultrasound contrast agent pharmacodynamics}

Ultrasound contrast agents comprise microspheres that approximate the size of red blood cells, so they remain strictly 
confined within the vessels. In contradistinction, iodine-based contrast agents and gadolinium comprise particles much smaller than red blood cells and these particles can freely diffuse across the vascular membrane into the interstitial space. These inherent differences between the pharmacodynamic properties of UCAs and CT/MRI contrast agents result in certain disparities between the enhancement patterns of focal liver lesions seen on CEUS and those seen on contrastenhanced CT and MRI. On CEUS, any enhancement observed represents true intravascular blood flow within vascular components of a lesion. On CT/MRI, both intravascular and extracellular pools of contrast agent contribute to parenchymal and lesional enhancement.

\section{Contrast-enhanced ultrasound enhancement phases}

The liver has a dual blood supply from the hepatic artery and main portal vein, contributing to approximately $25 \%$ and $75 \%$ of blood flow to the liver, respectively. As a result of this dual vascular supply, after intravenous contrast administration, different vascular structures in the normal liver reach peak enhancement at different times. Specifically, the hepatic arteries reach peak enhancement first, followed by the portal veins, and then the hepatic veins. This allows the distinction of three enhancement phases: the arterial phase, the portal venous phase and the late phase [42]. These three phases represent a continuum, with one phase gradually changing to the other. However, for clinical utility and communication purposes the following time intervals have been defined: the arterial phase starts 10-20 s after UCA injection and lasts up to 35-40 s; the portal venous phase starts at 30-45 s after UCA injection and lasts up to $120 \mathrm{~s}$; the late phase starts after $120 \mathrm{~s}$ until there is complete clearance of UCA from the circulation at approximately 4-6 $\min$ [42-44].

Contrast-enhanced ultrasound allows for real-time observation and recording of this continuum of enhancement through all phases from the moment of contrast injection until contrast is eliminated from the circulation - without the risk of ionizing radiation. In addition, UCA injection can be repeated if there is a need to confirm the findings, to clarify equivocal or inconclusive findings from the first CEUS examination, or to evaluate an additional lesion in the arterial phase [45].

Unlike CEUS, contrast-enhanced CT entails intermittent static image acquisition in standardized time intervals. Depending on the purpose of the investigation (i.e. whether it is an initial study or a follow-up study), a multiphase contrast-enhanced CT scan is performed for characterizing focal liver lesions, particularly in adults. At least two imaging phases are required for the initial characterization of most liver lesions; the arterial and portal venous enhancement phases are typically acquired at $20 \mathrm{~s}$ and $40-60 \mathrm{~s}$, respectively. For specific indications, an unenhanced study can be performed first (e.g., for intralesional hemorrhage, or detection of calcifications), and a late parenchymal phase at $90 \mathrm{~s}$ might also be acquired, although the former is generally not recommended in children [46].

Because of the significant burden of ionizing radiation involved in a multiphase CT scan, contrast-enhanced MRI is the imaging modality of choice for liver lesion characterization in many pediatric institutions [46]. With MRI, pre-contrast imaging is followed by dynamic post-contrast image acquisition in the arterial phase, the portal venous phase, and the delayed or equilibrium phases (2-5 min after injection). However, additional delayed images after $2-5 \mathrm{~min}$ can help characterize certain lesions such as hemangiomas and vascular malformations. If a hepatobiliary contrast agent is used, the hepatobiliary phase (typically at $20 \mathrm{~min}$ after injection with gadoxetate, and approximately $45 \mathrm{~min}$ with gadobenate) is also acquired [27, 47].

\section{Contrast-enhanced ultrasound enhancement terminology}

The conspicuity of a focal liver lesion during CEUS depends on the differential enhancement between the lesion and background normal hepatic parenchyma. Comparison of the lesion to the normal hepatic parenchyma is made at each enhancement phase. A lesion is characterized as non-enhancing if there is no contrast uptake. If during an enhancement phase there is equal, reduced or greater enhancement compared to the adjacent liver at the same depth, the lesion is characterized as iso-, hypo- or hyperenhancing, respectively [43]. Washout refers to the visible reduction of UCA signal in portions of or in the entire lesion that follows its initial maximum enhancement. Washout of a lesion is compared to the adjacent liver parenchyma during any phase. The presence of contrast washout is the main imaging feature of malignancy, whereas its absence suggests benignity [48]. The purely intravascular nature of UCA allows for better and more consistent determination of the washout feature. However, a child's comorbidities can affect interpretation of the washout of a focal liver lesion, e.g., underlying cirrhosis might be associated with poor enhancement of the background liver parenchyma and therefore less discrete washout.

\section{Contrast-enhanced ultrasound scanning technique}

Depending on the size and location of the lesion, transverse, sagittal or oblique images can be obtained. The examiner should select the scanning plane in which the target lesion is visualized in its entirety, if possible, and at the shortest possible distance from the transducer. In addition, in that same single imaging plane the lesion should be visualized along with a substantive part of the surrounding normal liver parenchyma, including adjacent vascular structures where possible. 
The timer should be started when the UCA is injected and should be visible throughout the study. The operator should hold the transducer stationary over the area of interest, observing and recording in a video clip the perfusion of the UCA within the lesion from the moment of injection and for at least $60 \mathrm{~s}$. This continuous phase is followed by intermittent imaging of the target lesion at 5-10 s, repeated every $30-60 \mathrm{~s}$ past 5 min or until the contrast agent has completely washed out from the rest of the liver [43, 49]. Additionally, after the first $60 \mathrm{~s}$, the examiner can intermittently scan through the rest of the liver in standard transverse and sagittal planes to look for additional lesions.

Care must be taken to avoid prolonged insonation over the region of interest, which can lead to microbubble destruction by acoustic energy. The extent of microbubble destruction depends on how long the probe is stationary, and the transducer frequency; UCA microbubbles in the nearfield are destroyed most quickly. If microbubble destruction occurs, it is possible to make erroneous conclusions by misinterpreting this loss of contrast signal as contrast washout [50]. If a second UCA dose is required, the examiner should ensure that the first UCA dose has been cleared from the circulation by allowing $10 \mathrm{~min}$ to pass between the first and second injections, or until contrast agent is no longer visible. Alternatively, one can use the flash technique with high mechanical index to quickly burst the microbubbles and clear the imaging field.

\section{Interpretation of contrast-enhanced ultrasound findings in benign liver lesions}

\section{Infantile hemangioma}

Infantile hemangioma is a benign vascular tumor of the liver and is the most common hepatic tumor in infants ( $<6$ months) with female predominance of 3:1 [51]. It is composed of large endothelial-lined vascular channels, similar to infantile hemangiomas elsewhere in the body [52]. The natural course is typical, with presentation shortly after birth, rapid proliferation in the first 6-12 months of age, and spontaneous regression and slow involution in the first 2-3 years of age [53]. These lesions are usually discovered during the proliferative phase because of associated hepatomegaly and abdominal distention, or during screening of infants with $>5$ cutaneous infantile hemangiomas. If there is extensive high-flow arteriovenous shunting within the lesion, high-output congestive heart failure can occur. Infantile hemangiomas are classified by subtypes as focal, multifocal and diffuse abnormalities [51, 54].

On gray-scale US, depending on the specific subtype, imaging appearances vary. Small, focal infantile hemangiomas appear as well-defined, predominantly hypoechoic lesions. Larger lesions tend to be heterogeneous, predominantly hypoechoic or of mixed echogenicity, with echogenic areas corresponding to the interfaces between the walls of the vascular channels and fibrosis. Anechoic areas correspond to the vascular channels or represent areas of necrosis. The diffuse subtype demonstrates near-complete replacement of the hepatic parenchyma with innumerable well-circumscribed nodules. Color Doppler US reveals enlarged peri- and intralesional arteries, veins and shunts $[55,56]$. Calcifications are seen in up to $36 \%$ of these children, usually with tumor involution [56].

The typical CEUS appearances of infantile hemangiomas are expected to mimic the well-described enhancement patterns reported for CT and MRI: in the early arterial phase, there is peripheral nodular (circular or semi-circular) enhancement; in the portal venous and late phases, there is centripetal progression and complete iso- or hyperenhancement of the lesion compared to the adjacent liver parenchyma, with subtle late washout possible (Fig. 1) [4, 5, 21, 57].

\section{Congenital hemangioma}

Congenital hemangioma is also a benign vascular lesion, with distinctly different histological and clinical features from those of infantile hemangioma. It occurs with equal frequency in female and male infants. Unlike infantile hemangiomas, a congenital hemangioma is typically present at birth but does not grow after birth $[52,58,59]$. Depending on the involution rate, congenital hemangiomas are divided into three categories: rapidly involuting congenital hemangiomas that begin to involute soon after birth (most of these have significantly decreased in size by 2 years of age); non-involuting congenital hemangiomas that do not involute or decrease in size over time; and partially involuting congenital hemangioma, in which the involution occurs during the first 12 months of age, at which point the rate of involution decreases over time [59].

In terms of imaging appearances, many congenital hemangiomas are indistinguishable from infantile hemangiomas (Fig. 2) [60]. They are most commonly solitary. On grayscale US, congenital hemangiomas typically appear as wellcircumscribed heterogeneous lesions. They can be hypo- or hyperechoic, containing multiple anechoic vascular spaces on color Doppler [21, 59]. In one recent study including children with congenital hemangiomas, $60 \%$ of the lesions were heterogeneous on gray-scale US and $40 \%$ of the lesions were hyperechoic. In this study, a heterogeneous appearance was noticed in larger lesions ( $>3 \mathrm{~cm}$ in diameter), whereas smaller lesions $(<1 \mathrm{~cm}$ in diameter) appeared predominantly hyperechoic [21]. Other distinctive features of congenital hemangiomas include more calcifications (specific for noninvoluting congenital hemangiomas and rapidly involuting congenital hemangiomas), larger flow voids like those of an arteriovenous malformation with associated solid components, and less well-defined margins on CT and MRI $[58,60]$.

The CEUS enhancement pattern of the congenital hemangio$\mathrm{ma}$ is similar to that of infantile hemangioma, demonstrating 

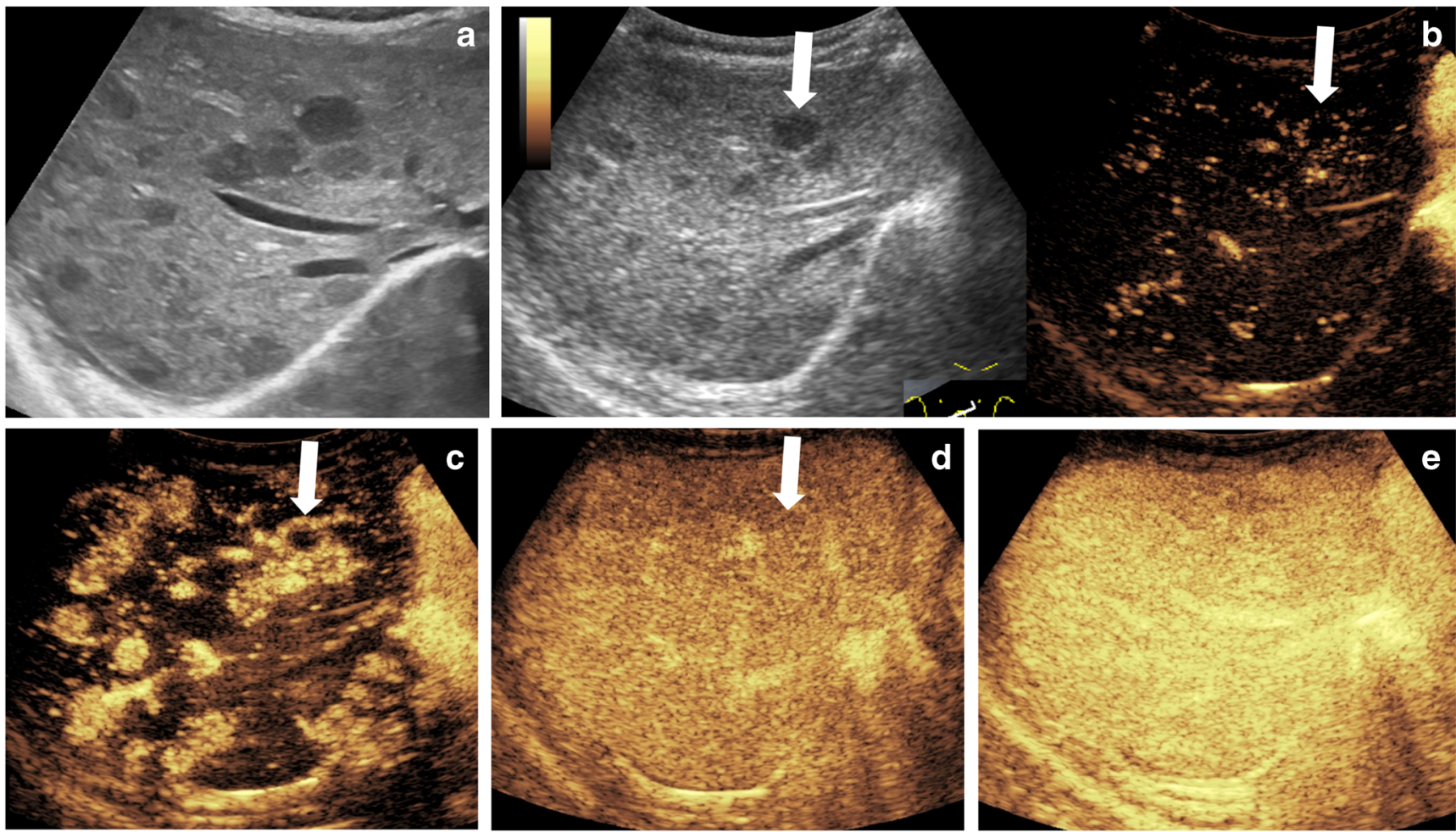

Fig. 1 Incidental liver hemangiomatosis in a 4-month-old boy. a Transverse gray-scale US shows multiple hypoechoic lesions throughout the liver. b-e Transverse contrast-enhanced ultrasound (CEUS) of the liver. Dual display of the gray-scale (left) and contrastenhanced (right) image at $8 \mathrm{~s}(\mathbf{b})$ and contrast-only CEUS images at $10 \mathrm{~s}$

typically peripheral nodular enhancement during the arterial phase, with centripetal continuous filling during the late portal venous phase (Fig. 3, Online Supplementary Material 1) [57]. In one study including five children with congenital hemangiomas who underwent CEUS, all lesions (100\%) showed hyperenhancement in the arterial phase, and most of the lesions $(80 \%)$ remained hyperenhancing relative to the normal liver parenchyma in the portal venous phase [21]. Larger lesions might have incomplete contrast fill-in [21].

\section{Focal nodular hyperplasia}

Focal nodular hyperplasia (FNH) is a benign tumor that is most frequently found in young to middle-age adults, though it is also encountered in the pediatric population, typically between the ages of 2 years and 5 years. It can also be seen in oncology patients following radiation and chemotherapy [1, 61]. People with FNH are rarely symptomatic, and FNH is often incidentally observed during imaging performed for other reasons.

Focal nodular hyperplasia is thought to represent a proliferative hepatocellular response caused by increased blood flow resulting from a dystrophic artery. Histologically, it is composed of benign-appearing hepatocytes arranged in nodules that are usually partially delineated by fibrous bands (c), $22 \mathrm{~s}(\mathbf{d})$ and $1 \mathrm{~min} 33 \mathrm{~s}(\mathbf{e})$ after contrast administration. Early peripheral enhancement is exemplified in the largest lesion (arrows), followed by centripetal enhancement and nearly complete and homogeneous enhancement of all lesions similar to the background hepatic parenchyma. No washout is noted in any of the lesions (e)

originating from the central fibrous scar that contains the dystrophic arterial vessels [62,63]. Atypical forms of FNH are also recognized, including FNH without a central scar (mostly smaller lesions less than $3 \mathrm{~cm}$ in diameter), and $\mathrm{FNH}$ with significant steatosis $[62,64]$. FNH does not bleed and does not have malignant potential. It can be solitary or multiple and can coexist with other benign or malignant lesions; therefore, accurate identification is crucial.

Because this lesion is composed of normal hepatocytes, on US it appears well-circumscribed and nearly isoechoic with the adjacent normal liver, although it can also be hypo- or, rarely, hyperechoic [65]. The central scar and radiating septa typically appear hyperechoic relative to the remainder of the lesion. Color Doppler US demonstrates radial arterial vascularity of the stellate scar in a spoke-wheel pattern [1].

In a recent pediatric CEUS study, classic FNH showed the presence of a central feeding artery that is visible in the early arterial phase and demonstrates a centrifugal filling pattern, with stellate (spoke-wheel) hyperenhancement in the arterial to early portal venous phases, and iso- or hyperenhancement in the late portal venous phase (Fig. 4, Online Supplementary Material 2) [7, 66].

There are some contradictory results regarding the correlation between the lesion size and the identification of the central stellate scar on CEUS. Some investigators showed that the 

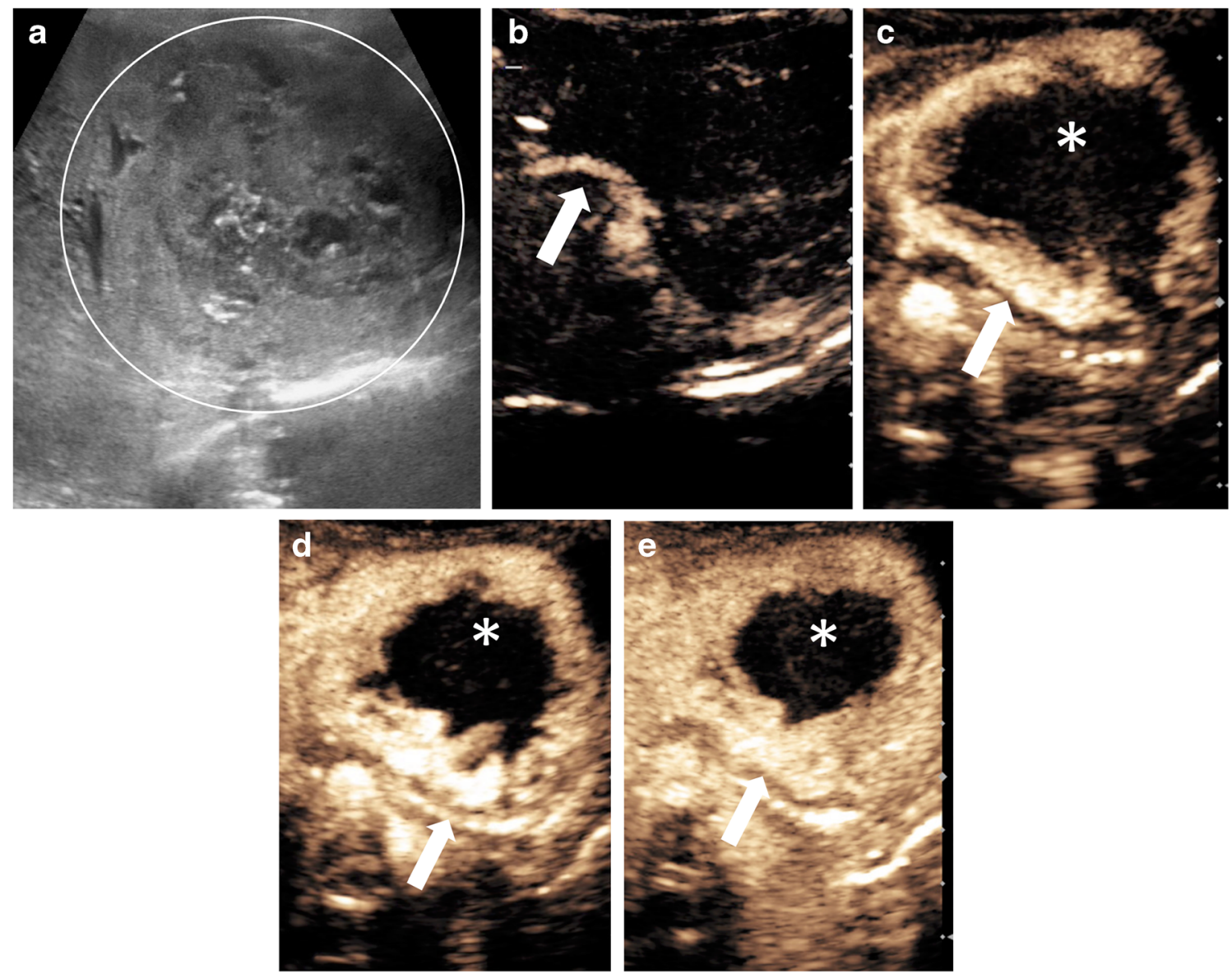

Fig. 2 Rapidly involuting congenital hemangioma in a 3-week-old boy with a congenital mass of the left liver lobe. a Transverse gray-scale US shows a large heterogeneous lesion (circle) within the left liver lobe. The volume of the lesion at initial scan was $41 \mathrm{~mL}$. b-e Transverse contrastenhanced ultrasound (CEUS) of the liver in contrast-only mode in the arterial phase at $11 \mathrm{~s}(\mathbf{b}), 14 \mathrm{~s}(\mathbf{c})$ and $18 \mathrm{~s} \mathrm{(d)}$, and in the portal venous phase $60 \mathrm{~s}$ after injection of the contrast agent (e). Rapid nodular enhancement progresses from the periphery (arrows) to the center, with

incomplete enhancement in the central aspect (asterisks) of the lesion. In the follow-up US scans (not shown) except for residual calcifications there was near-complete regression of the lesion. Imaging features are typical for rapidly involuting congenital hemangioma. In this child, at 9 months of age the volume of the lesion had decreased at $2.6 \mathrm{~mL}$, and at 5 years of age the lesion was barely visible with a measured residual volume of $0.4 \mathrm{~mL}$

classic spoke-wheel pattern depended on the size of the lesion and was more frequently seen in larger FNHs, typically those greater than $3 \mathrm{~cm}[67,68]$. Other investigators reported that the spoke-wheel pattern was not size-dependent and that centrifugal filling was seen more frequently in small FNHs (less than $3 \mathrm{~cm}$ in size) [67-70].

\section{Hepatic adenomas}

Hepatic adenomas are benign, typically solitary lesions that are frequently diagnosed in women ages 35-40 years. Although hepatic adenomas are very rare in children, they are encountered more often in young girls who take oral contraception, in children who are on steroid therapy and in those with underlying metabolic disease such as galactosemia and glycogen storage disease [62, 71]. A hepatic adenoma is composed of benign-appearing hepatocytes, which might contain increased amounts of fat and glycogen [14]. Hepatic adenoma

demonstrates a propensity to hemorrhage, particularly if large or exophytic in location; it rarely becomes malignant $[72,73]$. For these reasons hepatic adenomas are commonly treated with surgical resection.

On imaging, the appearance of hepatic adenoma depends on the composition of the lesion and of the surrounding liver, as well as the presence of associated complications (e.g., intralesional necrosis and hemorrhage). Uncomplicated hepatic adenomas on US tend to be homogeneous lesions with similar reflectivity to the adjacent normal liver, or they appear relatively hyperechoic if there is high intralesional lipid content. However, on a background of diffuse fatty liver infiltration or glycogen storage disease, adenomas might appear hypoechoic [1]. On color Doppler imaging, hepatic adenomas usually demonstrate multiple vascular channels located peripherally and centrally, with predominately venous flow [74]. Large hepatic adenomas, particularly those greater than $5 \mathrm{~cm}$, can be complicated with rupture and hemorrhage, which 
Fig. 3 Congenital hemangioma in a 2-week-old boy with elevated liver enzymes. a Transverse grayscale US demonstrates a large focal liver lesion (arrows). b-d Transverse contrast-enhanced ultrasound (CEUS) images in contrast-only mode during dynamic enhancement phases. In the arterial phase (b), the lesion demonstrates peripheral, nodular, discontinuous enhancement pattern (arrows). In the portal venous phase (c), the lesion (arrow) appears homogeneously hyperenhancing. In the late phase (d), the lesion (arrow) remains hyperenhancing compared to the adjacent liver parenchyma. See Online Supplementary Material 1 for cinematic clip
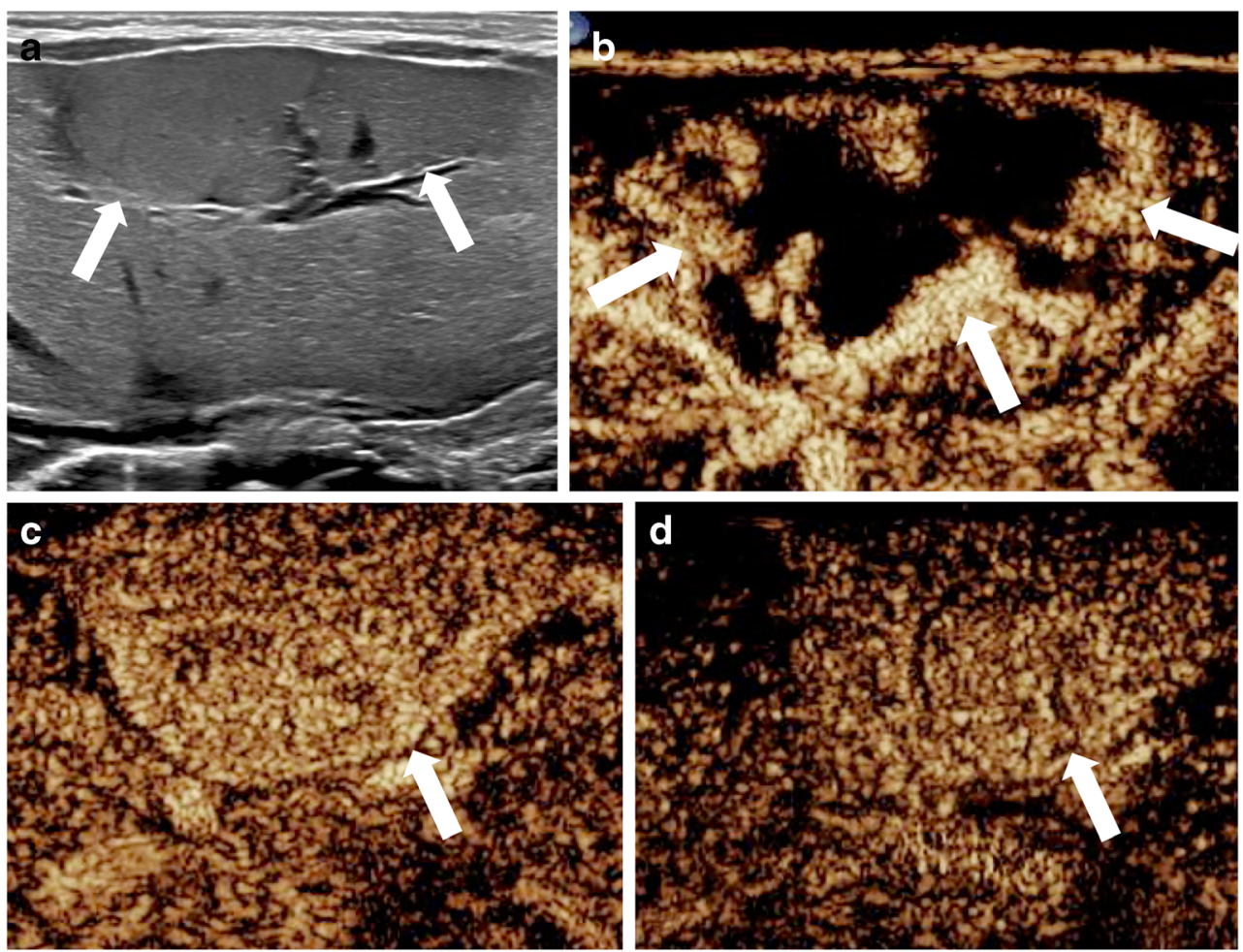

is most commonly intralesional; however, in rare instances intraperitoneal hemorrhage and hypovolemic shock occur [1].
On CEUS, hepatic adenomas typically display subcapsular feeding arteries, resulting in the following perfusion pattern:
Fig. 4 Focal nodular hyperplasia in a 17-year-old boy with abdominal pain. An incidentally detected focal liver lesion was found at gray-scale US (not shown here). a-d Transverse contrast-enhanced US images, in contrast-only mode during dynamic enhancement phases. In the early (a) and late (b) arterial phases, there is rapid spoke-wheel enhancement of the lesion (arrows) originating from the center (arrowhead). In the portal venous phase (c), the lesion (arrows) appears homogeneously hyperenhancing and remains hyperenhancing during the late phase (d), where a central hypoenhancing scar (arrowhead) is evident
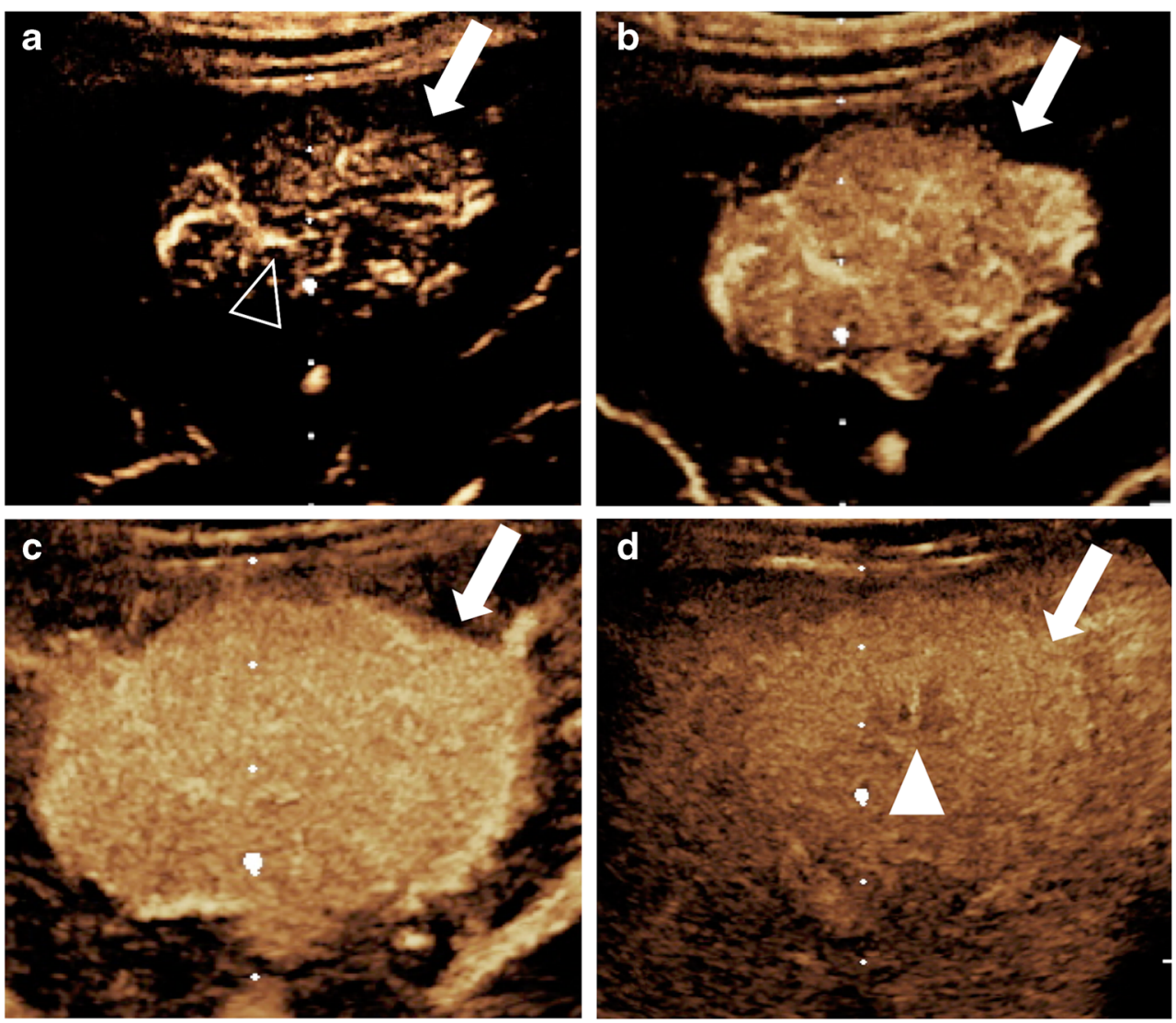

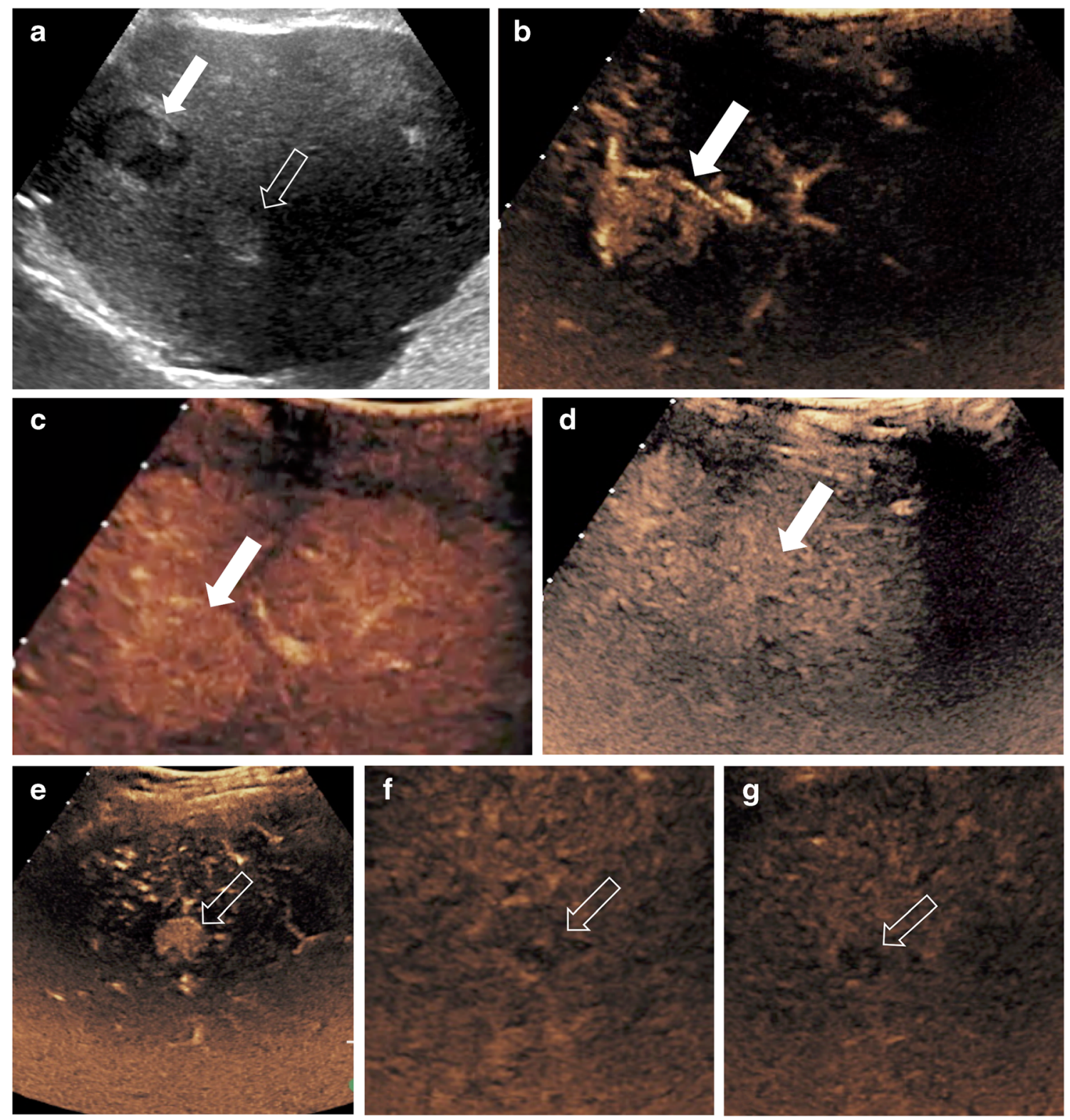

Fig. 5 Hepatic adenoma and hepatocellular carcinoma in a 17-year-old girl with glycogen storage disease type 1 who was known to have multiple hepatic adenomas. a Transverse gray-scale US demonstrates two focal liver lesions. The larger lesion (solid arrow) appears with heterogeneous echotexture but is predominantly hypoechoic, and the smaller lesion (open arrow) is hyperechoic. Both lesions were further evaluated with contrast-enhanced ultrasound (CEUS). b-d Transverse CEUS images of the first lesion (arrows) in contrast-only mode demonstrate hyperenhancement in the arterial phase (b), iso- to slightly hyperenhancement in the portal venous phase (c) and isoenhancement to background liver in the late phase (d). Histological diagnosis: hepatic adenoma. e-g Transverse CEUS in contrast-only mode of the second lesion (arrows) demonstrates hyperenhancement in the arterial phase (e) and hypoenhancement in the portal venous (f) and late (g) phases. Histological diagnosis: hepatocellular carcinoma rapid enhancement in the early arterial phase; homogeneous, complete or near-complete enhancement in the portal phase; and isoenhancement or, rarely, hyperenhancement that usually persists during the delayed phase, although slow progressive hypoenhancement has been reported (Fig. 5) [5, 62, 75-77]. Areas of intralesional hemorrhage appear as nonenhancing regions on CEUS.

\section{Focal fat or focal fatty sparing}

Fatty infiltration is defined as an excessive accumulation of fat within the hepatocytes. This process might not be uniform throughout the liver. Areas with less fat infiltration (spared) or increased fat deposition (focal or diffuse) can mimic liver lesions. Focal fatty changes are often located near the 
gallbladder fossa, in segment IV (near the falciform ligament) and at the bifurcation of the main portal vein [78].

On gray-scale US, focal fatty infiltration can appear as a distinct lesion or as less defined geographic areas of hyperechogenicity, whereas fatty sparing appears as geographic regions of hypoechogenicity [9]. In both cases, the echogenicity of the lesion is compared to that of the adjacent liver parenchyma. Although typical features on gray-scale US include wedge-shape appearance, location near gallbladder and falciform ligament, and penetration by branches of portal or hepatic veins, occasionally these regions raise concern for focal masses [78, 79].

On CEUS following UCA administration, areas of focal fat or fatty sparing are expected to enhance in a similar manner as the background liver, with no evidence of abnormal vessels (Fig. 6) [76].

One previous study evaluating the characteristics of focal fatty infiltration of 25 lesions in adults reported a variable frequency pattern in the arterial phase, including isoenhancement (44\%), hyperenhancement (12\%) and hypoenhancement (44\%). In the portal venous phase all lesions $(100 \%)$ demonstrated isoenhancement, and these areas could not be distinguished from adjacent liver tissue [80]. This variable enhancement in the arterial phase might be explained by altered portal flow dynamics; it was previously shown that areas of fatty liver infiltration adjacent to the liver hilum are supplied by a venous network that originates from the pancreatico-duodenal and pyloroduodenal veins rather than the portal vein [80]. Another explanation might be that extrinsic narrowing of the supplying blood vessels by the adjacent fatty infiltrated hepatic cells affects the degree of UCA enhancement.

\section{Regenerative nodules}

Regenerative nodules, also known as "nodular regenerative hyperplasia," occur as a hyperplastic response of hepatocytes to an insult. In the rare cases that they occur in children, they are often associated with conditions leading to chronic liver disease (e.g., myelo- and lymphoproliferative disorders, autoimmune disorders, collagen vascular disease) or to previous use of steroids and antineoplastic medication [14].

The appearance of regenerative nodules on US is variable and depends on the size of the nodules. Small nodules might not be apparent, but if there are many of them the liver appears with diffusely heterogeneous echotexture or distortion of normal architecture. If nodules are visible, they are generally well-circumscribed, homogeneous, and hypoechoic or hyperechoic compared with the normal liver [14, 81].

On CEUS these nodules show similar enhancement with the background liver parenchyma throughout all the enhancement phases. They are distinct from their malignant counterparts in that they do not show washout during the portal venous or late phases [82].

\section{Interpretation of contrast-enhanced ultrasound findings in hepatic malignancy}

Among the primary and secondary malignant hepatic tumors known in children are hepatoblastoma, hepatocellular carcinoma, undifferentiated (embryonal) sarcoma, angiosarcoma, embryonal rhabdomyosarcoma, lymphoma and metastasis. Their appearance is variable on gray-scale US and can overlap with that of benign lesions. A recent meta-analysis of 57 studies showed that CEUS has excellent diagnostic accuracy in differentiating malignant from benign focal liver lesions, with a pooled sensitivity and specificity of 0.92 (95\% confidence interval [CI]: 0.91-0.93) and 0.87 (95\% CI: $0.86-0.88$ ), respectively [83]. The average age of the patients in the studies included in this meta-analysis ranged from 13 years to 70 years; however, only one study was exclusively in pediatric patients [9]. The hallmark of both primary and metastatic malignant liver lesions is the washout of the contrast agent in any given phase, occurring mostly during the portal venous or delayed phases [42].

The arterial-phase enhancement pattern of malignant lesions can be variable. For example, hypervascular metastasis and hepatocellular carcinoma exhibit hyperenhancement during the arterial phase, while some metastases appear as hypoenhanced or demonstrate a rim-like enhancement in the arterial phase. Larger malignant lesions might show a disorganized internal vasculature, which becomes more visible on CEUS studies than it does on non-contrast ultrasound, CT or MRI.

It is important to consider that the enhancement pattern of hepatic inflammatory and infectious lesions on CEUS can be like those of primary liver malignancy and metastatic disease. Because of the hyperemia associated with infection, abscesses have a peripheral rim of hyperenhancement during the arterial phase of CEUS. If the central component is replaced by purulent material, then the center does not enhance. However, depending on the degree of liquefaction the central aspect might also be hypoenhancing or have a well-defined non-enhancing region surrounded by enhancing septations. During the venous phase, inflammatory and infectious lesions show hypoenhancement. These patterns can be indistinguishable from malignant lesions, and biopsy might be required if the history, clinical signs and symptoms are not clear [84, 85].

\section{Hepatoblastoma}

Hepatoblastoma is the most common primary malignant pediatric liver tumor, accounting for more than $90 \%$ of liver cancers in children younger than 5 years. It usually occurs sporadically, but it is sometimes associated with prematurity, Beckwith-Wiedemann syndrome, hemihypertrophy and familial adenomatous polyposis coli $[2,86]$. It presents with nonspecific abdominal symptoms, but the most common clinical presentation is a palpable abdominal mass; only 


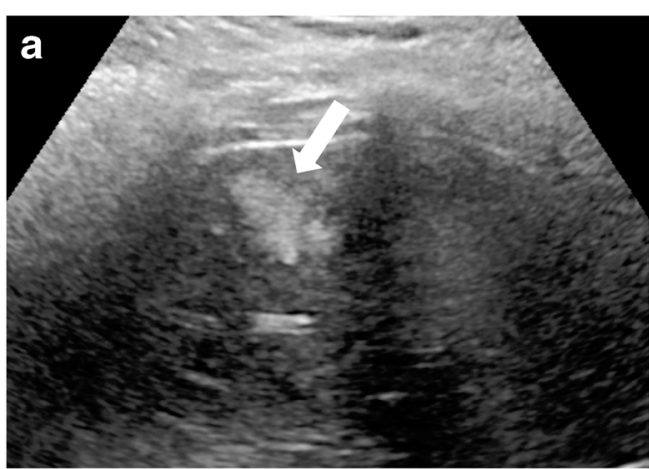

Fig. 6 Focal fatty infiltration of the liver in a 16-year-old girl who presented with elevated liver enzymes. a Transverse gray-scale US demonstrates a focal hyperechoic lesion (arrow) within the subcapsular region of the liver. $\mathbf{b}$ Contrast-enhanced ultrasound (CEUS) of the liver in

occasionally acute abdominal pain from intratumoral hemorrhage or rupture is encountered.

Hepatoblastoma is a well-circumscribed, encapsulated, large solid mass with a lobulated contour. Epithelial hepatoblastomas typically demonstrate a relatively more homogeneous appearance, while mixed epithelial and mesenchymal tumors appear markedly heterogeneous. Teratoid components appear cystic. Areas of hemorrhage or necrosis within the tumor are common [3]. Coarse calcifications are present in 20-50\% cases.

On CEUS hepatoblastoma can show early peripheral enhancement during the arterial phase and marked contrast washout during the late portal venous phase (Fig. 7) [4]. It can invade the portal or hepatic veins, and when this happens CEUS can accurately identify a tumor thrombus as an enhancing filling defect within the invaded vessel.

\section{Hepatocellular carcinoma}

Hepatocellular carcinoma (HCC) is the second most common primary malignant liver tumor in children, accounting for 20 $30 \%$ of primary hepatic malignancies. It is usually found in older children and adolescents (10-14 years) but has also been found in children younger than 5 years. Several diseases in children can lead to cirrhosis, which increases the risk of developing HCC (e.g., glycogen storage diseases, progressive familial intrahepatic cholestasis, biliary atresia, Alagille syndrome and Fontan hepatopathy) [87]. However, most cases of HCC occur in children without underlying liver disease [87, 88]. Additionally, there are two variants of HCC in the pediatric age group: the first is hepatocellular malignant neoplasm not otherwise specified (previously referred to as transitional liver cell tumor), which is composed of both hepatoblastoma and HCC components; the second is fibrolamellar HCC, which typically presents with normal alpha-fetoprotein levels and accounts for almost $30 \%$ of HCCs in people younger than 20 years [89-91].

The enhancement patterns of HCC on CEUS have been detailed in adults using the CEUS Liver Imaging Reporting and Data System (LI-RADS) [45]. This system characterizes a lesion as HCC using various visual CEUS imaging features: the lesion's size; the type and degree of arterial phase enhancement; and the presence, onset and degree of washout.

On CEUS, HCC typically demonstrates arterial-phase hyperenhancement, which can involve diffusely the whole lesion or a portion of the lesion (in what is known as nodule-in-nodule or mosaic appearance). Another typical feature is washout, which is late in onset (beginning $60 \mathrm{~s}$ after contrast injection) and mild in degree (the lesion becomes less enhanced than the surrounding liver but still demonstrates some degree of persistent contrast enhancement within 2 min after contrast injection) [45]. The CEUS imaging appearance is likely similar in children. Although fibrolamellar HCC is distinct from HCC, a case report of a CEUS in a child with fibrolamellar HCC described arterial hyperenhancement followed by washout of the tumor beginning approximately $40 \mathrm{~s}$ after contrast injection; hyperenhancement was also noted within the tumor thrombus in the portal vein (Online Supplementary Material 3) [92]. If there is early onset or marked washout, this suggests a malignant tumor other than HCC (Fig. 5).

\section{Metastatic disease}

A common feature of all metastatic liver lesions on CEUS is contrast washout, which is typically rapid (beginning within $60 \mathrm{~s}$ after contrast injection) and marked (the lesion is completely devoid of contrast within 2 min after contrast injection), resulting in a "punched-out" appearance (Online Supplementary Material 4) [45]. In the arterial phase, however, metastasis can appear as hyperenhancing or hypoenhancing lesions with variable patterns, including homogeneous, rimlike or heterogeneous patterns $[49,93]$.

Differentiating between benign cystic lesions and cystic hepatic metastasis can be challenging on gray-scale imaging. On CEUS, though, the distinction is clearer: cystic hepatic metastasis might show peripheral rim-like hyperenhancement 

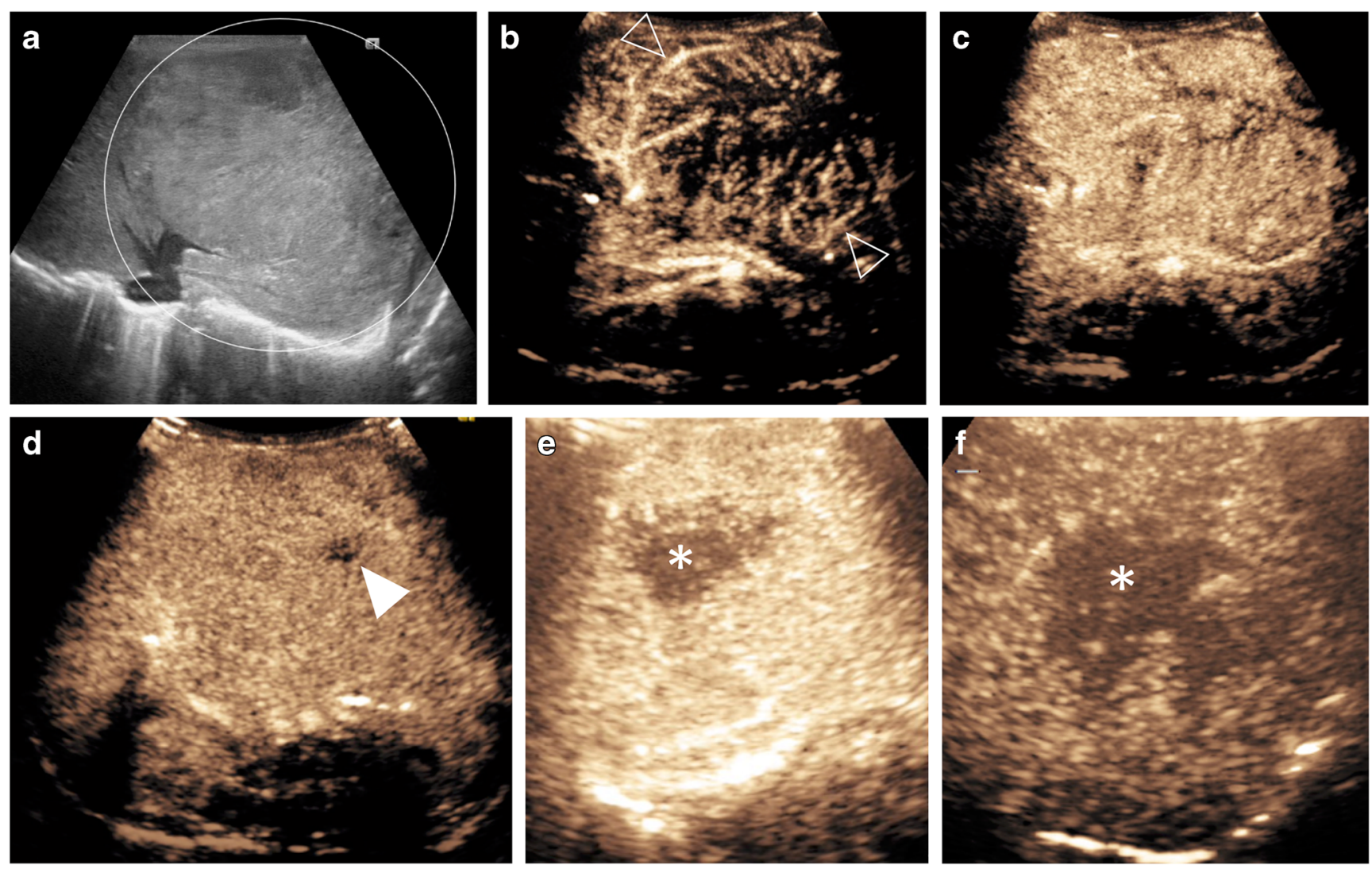

Fig. 7 Hepatoblastoma in an 11-day-old boy with a large congenital mass of the left liver lobe. a Gray-scale US shows a large mass with heterogeneous echotexture (circle) within the left liver lobe. b-f Contrast-enhanced ultrasound (CEUS) of the liver. Transverse CEUS in contrast-only mode in arterial phase at $10 \mathrm{~s} \mathrm{(b)}$ and $14 \mathrm{~s} \mathrm{(c),} \mathrm{in} \mathrm{portal}$ venous phase at $53 \mathrm{~s}(\mathbf{d})$ and in late-phase of enhancement $>120 \mathrm{~s}$ after

in the arterial phase, while benign cysts usually do not show any enhancement [94]. However, unlike benign cystic lesions, all cystic metastatic lesions show contrast washout of the enhancing areas during the portal venous or the late venous phases $[94,95]$. When CEUS was used in addition to grayscale US to distinguish between benign (hemorrhagic cyst, hemangiomas) and malignant cyst-like focal liver lesions, the sensitivity, specificity, and positive and negative predictive values all increased significantly. Similarly, when CEUS was used to assess focal liver lesions, better interobserver agreement was reported [95].

\section{Other malignant hepatic lesions}

Trenker et al. [96] documented CEUS appearances of hepatic lymphoma in a cohort of 38 adults. In their study, lymphoma was hypoechoic on gray-scale imaging in $97.4 \%$ of cases and demonstrated variable enhancement in the arterial phase with $23.7 \%, 44.7 \%$ and $31.6 \%$ of lesions appearing hyper-, iso- and hypoenhancing, respectively. When compared to the background liver, $94.7 \%$ were hypoenhancing in the portal venous phase and all were hypoenhancing in the late parenchymal phase. The lack contrast injection (e, f). Rapid heterogeneous enhancement shows multiple irregular vessels (open arrowheads) centrally within the lesion in a disorganized pattern. One small region in the periphery of the lesion (solid arrowhead) shows persistent reduced enhancement, possibly corresponding to necrosis. Transverse CEUS during the late phase (e and later $\mathbf{f}$ ) shows progressive washout (asterisks) centrally

of a consistent enhancement pattern makes it impossible to definitively distinguish hepatic lymphoma from other solid malignant lesions. However, the fact that lymphomas do not tend to distort the native vessels can be used as a sign to differentiate them from other malignant tumors.

\section{Comparative studies}

The safety and diagnostic accuracy of CEUS for characterizing focal liver lesions in adults have been well established. A prospective multicenter study of 1,349 mostly adult patients showed that CEUS has a $95.8 \%$ sensitivity in identifying malignant lesions [97]. The diagnostic performance of CEUS is described in Table $2[66,67,75,83,97-104]$. However, at this point the studies for hepatic CEUS application in children are relatively limited.

In children, one study demonstrated that CEUS had a $98 \%$ specificity and $100 \%$ negative predictive value for distinguishing benign from malignant liver lesions, using CT, MRI or histology as reference standards [9]. In that cohort of 44 children, only one lesion was falsely identified as being malignant on CEUS as well 
Table 2 Contrast-enhanced ultrasound (CEUS) diagnostic performance

\begin{tabular}{|c|c|c|c|c|}
\hline Reference $^{\mathrm{a}}$ & $\begin{array}{l}\text { Age range } \\
\text { (years) }\end{array}$ & $\begin{array}{l}\text { Subjects } \\
(n)\end{array}$ & CEUS application & CEUS performance \\
\hline \multicolumn{5}{|l|}{ Meta-analysis } \\
\hline $\mathrm{Wu} 2018[83]^{\mathrm{b}}$ & $13-70$ & $57^{\mathrm{c}}$ & FLL & $\begin{array}{l}\text { Pooled: Sn 0.92; Sp 0.87; } \\
\quad \text { OR 104.20 }\end{array}$ \\
\hline \multicolumn{5}{|l|}{ Prospective studies } \\
\hline Strobel 2011 [98] & $12-91$ & 1,349 & Small FLLs $\leq 20 \mathrm{~mm}$ & $\begin{array}{l}\text { Acc } 83.8 \% \text {; Sn } 93.5 \% ; \text { Sp } 66.7 \% \\
\text { PPV } 92.3 \% \text {; NPV } 95.1 \%\end{array}$ \\
\hline Strobel 2009 [99] & $12-91$ & 1,349 & $\begin{array}{l}\text { Vascular characteristics } \\
\text { of FLLs }\end{array}$ & $\begin{array}{l}\text { Acc } 83.1 \% \text { benign lesions } \\
\text { Acc } 95.8 \% \text { malignant lesions } \\
\text { Acc } 91.4 \% \text { liver metastases } \\
\text { Acc } 84.9 \% \text { HCC }\end{array}$ \\
\hline Strobel 2008 [97] & $12-91$ & 1,349 & Differentiation of FLLs & $\begin{array}{l}\text { Acc } 90.3 \% ; \text { Sn } 95.8 \% ; \text { Sp } 83.1 \% \\
\text { PPV 95.4\%; NPV } 95.7 \%\end{array}$ \\
\hline $\begin{array}{l}\text { Ungermann } 2007 \\
\text { [67] }\end{array}$ & $17-81$ & 28 & Enhancement pattern of FNH & $\begin{array}{l}\text { Stellate enhancement in } 95 \% \text { lesions }>3 \mathrm{~cm} \text { and } 30 \% \\
<3 \mathrm{~cm} \text {; central scar in } 85 \% \text { lesions }>3 \\
\mathrm{~cm} \text { and } 20 \%<3 \mathrm{~cm}\end{array}$ \\
\hline $\mathrm{Wu} 2006[100]$ & $16-78$ & 79 & $\begin{array}{l}\text { Role to localize FLLs for } \\
\text { biopsy and diagnostic } \\
\text { accuracy of biopsy }\end{array}$ & $\begin{array}{l}\text { Acc biopsy significantly higher with CEUS than } \\
\text { US, } 95.3 \% \text { vs. } 87.4 \% \text {, respectively; Acc biopsy } \\
\text { malignant lesions significantly higher with CEUS } \\
\text { than US, } 97.1 \% \text { vs. } 78.8 \% \text {, respectively }\end{array}$ \\
\hline \multicolumn{5}{|l|}{ Retrospective studies } \\
\hline Kong 2015 [75] & $15-54$ & 38 & $\begin{array}{l}\text { Enhancement pattern FNH and } \\
\text { hepatic adenoma }\end{array}$ & $\begin{array}{l}39.5 \% \text { of lesions were correctly assessed with color } \\
\text { Doppler US alone; } 65.8 \% \text { of lesions were correctly } \\
\text { assessed with color Doppler US and CEUS }\end{array}$ \\
\hline Pei 2012 [101] & $15-75$ & 130 & $\begin{array}{l}\text { Quantitative perfusion } \\
\text { analysis of HCCs }\end{array}$ & $\begin{array}{l}\text { Washout time faster for poorly differentiated HCCs } \\
\text { than for moderately and well-differentiated HCCs }\end{array}$ \\
\hline Rennert 2011 [102] & $0.3-85.0$ & 100 & $\begin{array}{l}\text { Image fusion and surgical } \\
\text { planning for FLLs }\end{array}$ & $\begin{array}{l}\text { Image fusion allowed identification of additional } \\
\text { lesions in } 12 \text { patients, changing management }\end{array}$ \\
\hline $\operatorname{Kim} 2008[66]^{\mathrm{d}}$ & $14-81$ & 62 & $\begin{array}{l}\text { Differentiate FNH and hepatic } \\
\text { adenoma }\end{array}$ & $\begin{array}{l}\text { Sn } 95 \% \text { and } 86 \% ; \text { Sp } 74 \% \text { and } 79 \% \text {; PPV } 89 \% \\
\text { and } 90 \% ; \text { NPV } 88 \% \text { and } 71 \% \text {, for two readers, } \\
\text { respectively }\end{array}$ \\
\hline Wang 2008 [103] & $17-86$ & 52 & Undetermined FLL in fatty liver & Acc $91 \%$; Sn $91.7 \%$; Sp 90.9\% \\
\hline Soye 2007 [104] & $17-83$ & 68 & Characterize FLL & Sn $95 \% ;$ Sp $97.9 \%$ \\
\hline
\end{tabular}

$A c c$ accuracy, $F L L$ focal liver lesion, $F N H$ focal nodular hyperplasia, $H C C$ hepatocellular carcinoma, $N P V$ negative predictive value, $O R$ odds ratio, $P P V$ positive predictive value, $S n$ sensitivity, $S p$ specificity

${ }^{\text {a }}$ Original research, contrast-enhanced ultrasound (CEUS) studies including a mixed population of children and adults for focal liver lesions. All studies used SonoVue except where indicated

${ }^{\mathrm{b}}$ Included studies used SonoVue, Sonazoid (GE Healthcare, Milwaukee, WI), Optison and Definity

${ }^{c}$ Number of CEUS studies. In all other studies the number of subjects is presented

${ }^{\mathrm{d}}$ Contrast agent not specified

as on CT and MRI; however, histology at the time of resection indicated that it was a hepatic adenoma [9]. In another pediatric CEUS study, the investigators reported that CEUS had a sensitivity of $82 \%$, specificity of $100 \%$, negative predictive value (NPV) of $88 \%$ and positive predictive value (PPV) of $100 \%$ for correctly differentiating between benign and malignant lesions, using CT, MRI or histology as reference standards [15]. In a cohort of 30 children with definitive or probable hepatic adenoma and FNH, CEUS features were concordant with histology and MRI in $77.8 \%$ and $67.9 \%$ of cases, respectively; those investigators showed that by combining findings from MRI and CEUS, the proportion of lesions that could be classified as FNH or hepatic adenoma increased to 96.4\% [7]. Most important, performing CEUS as the initial imaging examination can help avoid further imaging with $\mathrm{CT}$ or MR or even prevent the need for a biopsy. Yusuf et al. [8] conducted CEUS of the liver in 147 pediatric patients and were able to avoid any further diagnostic or interventional procedure in 73 (49.7\%) of them.

\section{Limitations}

One disadvantage of CEUS when compared to CT and MR is that CEUS is more operator-dependent. Therefore, diagnostic 
accuracy is limited by the operator's ability to interrogate the abnormality. Another challenge when using CEUS is the inability to assess multiple lesions in the liver when they are not visible within a single field of view. However, this obstacle can be overcome either by evaluating additional lesions with subsequent injections of UCA or with transducer sweeps through the liver in the transverse and sagittal planes after the dynamic phase. These sweeps can identify lesions as they demonstrate washout, which is the key feature of malignancy.

\section{Conclusion}

Recent FDA approval of Lumason for intravenous liver applications in children has facilitated the widespread use of CEUS in the evaluation of focal liver lesions. CEUS is the ideal adjunct to gray-scale US when focal liver lesions are indeterminate. CEUS, with its ability to accurately distinguish between benign and malignant lesions, improves patient management by enabling a definite diagnosis in most cases. In fact, CEUS is so effective that it can often replace other cross-sectional imaging or interventional procedures. Although much more research is to be done on pediatric applications, CEUS promises ease and accuracy in the clinical setting.

Supplementary Information The online version contains supplementary material available at https://doi.org/10.1007/s00247-021-04976-2.

\section{Compliance with ethical standards}

Conflicts of interest Dr. Back has received an educational grant from Bracco Diagnostics.

Open Access This article is licensed under a Creative Commons Attribution 4.0 International License, which permits use, sharing, adaptation, distribution and reproduction in any medium or format, as long as you give appropriate credit to the original author(s) and the source, provide a link to the Creative Commons licence, and indicate if changes were made. The images or other third party material in this article are included in the article's Creative Commons licence, unless indicated otherwise in a credit line to the material. If material is not included in the article's Creative Commons licence and your intended use is not permitted by statutory regulation or exceeds the permitted use, you will need to obtain permission directly from the copyright holder. To view a copy of this licence, visit http://creativecommons.org/licenses/by/4.0/.

\section{References}

1. Chung EM, Cube R, Lewis RB, Conran RM (2010) From the archives of the AFIP: pediatric liver masses: radiologicpathologic correlation part 1. Benign Tumors Radiographics 30: $801-826$
2. Darbari A, Sabin KM, Shapiro CN, Schwarz KB (2003) Epidemiology of primary hepatic malignancies in U.S. children. Hepatology 38:560-566

3. Chung EM, Lattin GE Jr, Cube R et al (2011) From the archives of the AFIP: pediatric liver masses: radiologic-pathologic correlation. Part 2. Malignant tumors. Radiographics 31:483-507

4. Anupindi SA, Biko DM, Ntoulia A et al (2017) Contrastenhanced US assessment of focal liver lesions in children. Radiographics 37:1632-1647

5. El-Ali AM, Davis JC, Cickelli JM, Squires JH (2019) Contrastenhanced ultrasound of liver lesions in children. Pediatr Radiol 49: $1422-1432$

6. Piskunowicz M, Kosiak W, Batko T et al (2015) Safety of intravenous application of second-generation ultrasound contrast agent in children: prospective analysis. Ultrasound Med Biol 41:10951099

7. Fang C, Bernardo S, Sellars ME et al (2019) Contrast-enhanced ultrasound in the diagnosis of pediatric focal nodular hyperplasia and hepatic adenoma: interobserver reliability. Pediatr Radiol 49: 82-90

8. Yusuf GT, Sellars ME, Deganello A et al (2017) Retrospective analysis of the safety and cost implications of pediatric contrastenhanced ultrasound at a single center. AJR Am J Roentgenol 208:446-452

9. Jacob J, Deganello A, Sellars ME et al (2013) Contrast enhanced ultrasound (CEUS) characterization of grey-scale sonographic indeterminate focal liver lesions in pediatric practice. Ultraschall Med 34:529-540

10. Luo XL, Liu D, Yang JJ et al (2009) Primary gastrointestinal stromal tumor of the liver: a case report. World J Gastroenterol 15:3704-3707

11. Mandry D, Bressenot A, Galloy MA et al (2007) Contrastenhanced ultrasound in fibro-lamellar hepatocellular carcinoma: a case report. Ultraschall Med 28:547-552

12. Pschierer K, Grothues D, Rennert J et al (2015) Evaluation of the diagnostic accuracy of CEUS in children with benign and malignant liver lesions and portal vein anomalies. Clin Hemorheol Microcirc 61:333-345

13. Torres A, Koskinen SK, Gjertsen H, Fischler B (2017) Contrastenhanced ultrasound using sulfur hexafluoride is safe in the pediatric setting. Acta Radiol 58:1395-1399

14. Chiorean L, Cui XW, Tannapfel A et al (2015) Benign liver tumors in pediatric patients - review with emphasis on imaging features. World J Gastroenterol 21:8541-8561

15. Knieling F, Strobel D, Rompel O et al (2016) Spectrum, applicability and diagnostic capacity of contrast-enhanced ultrasound in pediatric patients and young adults after intravenous application - a retrospective trial. Ultraschall Med 37:619-626

16. Laugesen NG, Nolsoe CP, Rosenberg J (2017) Clinical applications of contrast-enhanced ultrasound in the pediatric work-up of focal liver lesions and blunt abdominal trauma: a systematic review. Ultrasound Int Open 3:E2-E7

17. Stenzel M, Mentzel HJ (2014) Ultrasound elastography and contrast-enhanced ultrasound in infants, children and adolescents. Eur J Radiol 83:1560-1569

18. Ntoulia A, Anupindi SA, Darge K, Back SJ (2018) Applications of contrast-enhanced ultrasound in the pediatric abdomen. Abdom Radiol 43:948-959

19. Riccabona M (2012) Application of a second-generation US contrast agent in infants and children - a European questionnairebased survey. Pediatr Radiol 42:1471-1480

20. Rosado E, Riccabona M (2016) Off-label use of ultrasound contrast agents for intravenous applications in children: analysis of the existing literature. J Ultrasound Med 35:487-496

21. El-Ali AM, McCormick A, Thakrar D et al (2020) Contrastenhanced ultrasound of congenital and infantile hemangiomas: 
preliminary results from a case series. AJR Am J Roentgenol 214: 658-664

22. Piscaglia F, Bolondi L, Italian Society for Ultrasound in Medicine and Biology (SIUMB) Study Group on Ultrasound Contrast Agents (2006) The safety of Sonovue in abdominal applications: retrospective analysis of 23,188 investigations. Ultrasound Med Biol 32:1369-1375

23. Katayama H, Yamaguchi K, Kozuka T et al (1990) Adverse reactions to ionic and nonionic contrast media. A report from the Japanese Committee on the Safety of Contrast Media. Radiology 175:621-628

24. Cochran ST, Bomyea K, Sayre JW (2001) Trends in adverse events after IV administration of contrast media. AJR Am J Roentgenol 176:1385-1388

25. Dillman JR, Strouse PJ, Ellis JH et al (2007) Incidence and severity of acute allergic-like reactions to i.v. nonionic iodinated contrast material in children. AJR Am J Roentgenol 188:1643-1647

26. Wang CL, Cohan RH, Ellis JH et al (2008) Frequency, outcome, and appropriateness of treatment of nonionic iodinated contrast media reactions. AJR Am J Roentgenol 191:409-415

27. Frydrychowicz A, Lubner MG, Brown JJ et al (2012) Hepatobiliary MR imaging with gadolinium-based contrast agents. J Magn Reson Imaging 35:492-511

28. Murphy KJ, Brunberg JA, Cohan RH (1996) Adverse reactions to gadolinium contrast media: a review of 36 cases. AJR Am J Roentgenol 167:847-849

29. Li A, Wong CS, Wong MK et al (2006) Acute adverse reactions to magnetic resonance contrast media - gadolinium chelates. Br J Radiol 79:368-371

30. Prince MR, Zhang H, Zou Z et al (2011) Incidence of immediate gadolinium contrast media reactions. AJR Am J Roentgenol 196: W138-W143

31. Mithal LB, Patel PS, Mithal D et al (2017) Use of gadoliniumbased magnetic resonance imaging contrast agents and awareness of brain gadolinium deposition among pediatric providers in North America. Pediatr Radiol 47:657-664

32. Weller A, Barber JL, Olsen OE (2014) Gadolinium and nephrogenic systemic fibrosis: an update. Pediatr Nephrol 29:1927-1937

33. McCarville MB (2011) Contrast-enhanced sonography in pediatrics. Pediatr Radiol 41:S238-S242

34. McCarville MB, Coleman JL, Guo J et al (2016) Use of quantitative dynamic contrast-enhanced ultrasound to assess response to antiangiogenic therapy in children and adolescents with solid malignancies: a pilot study. AJR Am J Roentgenol 206:933-939

35. McCarville MB, Kaste SC, Hoffer FA et al (2012) Contrastenhanced sonography of malignant pediatric abdominal and pelvic solid tumors: preliminary safety and feasibility data. Pediatr Radiol 42:824-833

36. Franke D, Daugherty RJ, Ključevšek D et al (2020) Contrastenhanced ultrasound of transplant organs - liver and kidney in children. Pediatr Radiol. https://doi.org/10.1007/s00247-02004867-y

37. Paltiel HJ, Barth RA, Bruno C et al (2020) Contrast-enhanced ultrasound of blunt abdominal trauma in children. Pediatr Radiol. https://doi.org/10.1007/s00247-020-04869-w

38. Acord MR, Cahill AM, Durand R et al (2020) Contrast-enhanced ultrasound in pediatric interventional radiology. Pediatr Radiol. https://doi.org/10.1007/s00247-020-04853-4

39. Stenzel M (2013) Intravenous contrast-enhanced sonography in children and adolescents - a single center experience. J Ultrason 13:133-144

40. Hwang M, Back SJ, Didier RA et al (2020) Pediatric contrastenhanced ultrasound: optimization of techniques and dosing. Pediatr Radiol. https://doi.org/10.1007/s00247-020-04812-z
41. No authors listed (2020) AIUM practice parameter for the performance of contrast-enhanced ultrasound examinations. J Ultrasound Med 39:421-429

42. Claudon M, Dietrich CF, Choi BI et al (2013) Guidelines and good clinical practice recommendations for contrast enhanced ultrasound (CEUS) in the liver — update 2012: a WFUMBEFSUMB initiative in cooperation with representatives of AFSUMB, AIUM, ASUM, FLAUS and ICUS. Ultraschall Med 34:11-29

43. Lyshchik A, Kono Y, Dietrich CF et al (2018) Contrast-enhanced ultrasound of the liver: technical and lexicon recommendations from the ACR CEUS LI-RADS working group. Abdom Radiol 43:861-879

44. Dietrich CF, Nolsoe CP, Barr RG et al (2020) Guidelines and good clinical practice recommendations for contrast enhanced ultrasound (CEUS) in the liver - update 2020 WFUMB in cooperation with EFSUMB, AFSUMB, AIUM, and FLAUS. Ultraschall Med Biol 46:2579-2604

45. Wilson SR, Lyshchik A, Piscaglia F et al (2018) CEUS LI-RADS: algorithm, implementation, and key differences from CT/MRI. Abdom Radiol 43:127-142

46. Schooler GR, Squires JH, Alazraki A et al (2020) Pediatric hepatoblastoma, hepatocellular carcinoma, and other hepatic neoplasms: consensus imaging recommendations from American College of Radiology Pediatric Liver Reporting and Data System (LI-RADS) working group. Radiology 296:493-497

47. Chavhan GB, Shelmerdine S, Jhaveri K, Babyn PS (2016) Liver MR imaging in children: current concepts and technique. Radiographics 36:1517-1532

48. Yang HK, Burns PN, Jang HJ et al (2019) Contrast-enhanced ultrasound approach to the diagnosis of focal liver lesions: the importance of washout. Ultrasonography 38:289-301

49. Schellhaas B, Strobel D (2019) Tips and tricks in contrastenhanced ultrasound (CEUS) for the characterization and detection of liver malignancies. Ultraschall Med 40:404-424

50. Greis C (2014) Technical aspects of contrast-enhanced ultrasound (CEUS) examinations: tips and tricks. Clin Hemorheol Microcirc 58:89-95

51. Gnarra M, Behr G, Kitajewski A et al (2016) History of the infantile hepatic hemangioma: from imaging to generating a differential diagnosis. World J Clin Pediatr 5:273-280

52. Merrow AC, Gupta A, Patel MN, Adams DM (2016) 2014 revised classification of vascular lesions from the International Society for the Study of vascular anomalies: radiologic-pathologic update. Radiographics 36:1494-1516

53. Iacobas I, Phung TL, Adams DM et al (2018) Guidance document for hepatic hemangioma (infantile and congenital) evaluation and monitoring. J Pediatr 203:294-300.e2

54. Kulungowski AM, Alomari AI, Chawla A et al (2012) Lessons from a liver hemangioma registry: subtype classification. J Pediatr Surg 47:165-170

55. Xu M, Pan FS, Wang $\mathrm{W}$ et al (2018) The value of clinical and ultrasound features for the diagnosis of infantile hepatic hemangioma: comparison with contrast-enhanced CT/MRI. Clin Imaging 51:311-317

56. Kassarjian A, Zurakowski D, Dubois J et al (2004) Infantile hepatic hemangiomas: clinical and imaging findings and their correlation with therapy. AJR Am J Roentgenol 182:785-795

57. Piorkowska MA, Dezman R, Sellars ME et al (2018) Characterization of a hepatic haemangioma with contrast-enhanced ultrasound in an infant. Ultrasound 26:178-181

58. Gorincour G, Kokta V, Rypens F et al (2005) Imaging characteristics of two subtypes of congenital hemangiomas: rapidly involuting congenital hemangiomas and non-involuting congenital hemangiomas. Pediatr Radiol 35:1178-1185 
59. Berenguer B, Mulliken JB, Enjolras O et al (2003) Rapidly involuting congenital hemangioma: clinical and histopathologic features. Pediatr Dev Pathol 6:495-510

60. Restrepo R, Palani R, Cervantes LF et al (2011) Hemangiomas revisited: the useful, the unusual and the new. Part 1: overview and clinical and imaging characteristics. Pediatr Radiol 41:895-904

61. Smith EA, Salisbury S, Martin R, Towbin AJ (2012) Incidence and etiology of new liver lesions in pediatric patients previously treated for malignancy. AJR Am J Roentgenol 199:186-191

62. European Association for the Study of the Liver (2016) EASL clinical practice guidelines on the management of benign liver tumours. J Hepatol 65:386-398

63. Bioulac-Sage P, Cubel G, Balabaud C, Zucman-Rossi J (2011) Revisiting the pathology of resected benign hepatocellular nodules using new immunohistochemical markers. Semin Liver Dis 31: 91-103

64. Ronot M, Paradis V, Duran R et al (2013) MR findings of steatotic focal nodular hyperplasia and comparison with other fatty tumours. Eur Radiol 23:914-923

65. Hussain SM, Terkivatan T, Zondervan PE et al (2004) Focal nodular hyperplasia: findings at state-of-the-art MR imaging, US, CT, and pathologic analysis. Radiographics 24:3-17

66. Kim TK, Jang HJ, Burns PN et al (2008) Focal nodular hyperplasia and hepatic adenoma: differentiation with low-mechanicalindex contrast-enhanced sonography. AJR Am J Roentgenol 190:58-66

67. Ungermann L, Elias P, Zizka J et al (2007) Focal nodular hyperplasia: spoke-wheel arterial pattern and other signs on dynamic contrast-enhanced ultrasonography. Eur J Radiol 63:290-294

68. Bartolotta TV, Taibbi A, Matranga D et al (2010) Hepatic focal nodular hyperplasia: contrast-enhanced ultrasound findings with emphasis on lesion size, depth and liver echogenicity. Eur Radiol 20:2248-2256

69. Wang W, Chen LD, Lu MD et al (2013) Contrast-enhanced ultrasound features of histologically proven focal nodular hyperplasia: diagnostic performance compared with contrast-enhanced CT. Eur Radiol 23:2546-2554

70. Bertin C, Egels S, Wagner M et al (2014) Contrast-enhanced ultrasound of focal nodular hyperplasia: a matter of size. Eur Radiol 24:2561-2571

71. Labrune P, Trioche P, Duvaltier I et al (1997) Hepatocellular adenomas in glycogen storage disease type I and III: a series of 43 patients and review of the literature. J Pediatr Gastroenterol Nutr 24:276-279

72. Ichikawa T, Federle MP, Grazioli L, Nalesnik M (2000) Hepatocellular adenoma: multiphasic CT and histopathologic findings in 25 patients. Radiology 214:861-868

73. Stoot JH, Coelen RJ, De Jong MC, Dejong CH (2010) Malignant transformation of hepatocellular adenomas into hepatocellular carcinomas: a systematic review including more than 1,600 adenoma cases. HPB 12:509-522

74. Bartolozzi C, Lencioni R, Paolicchi A et al (1997) Differentiation of hepatocellular adenoma and focal nodular hyperplasia of the liver: comparison of power Doppler imaging and conventional color Doppler sonography. Eur Radiol 7:1410-1415

75. Kong WT, Wang WP, Huang BJ et al (2015) Contrast-enhanced ultrasound in combination with color Doppler ultrasound can improve the diagnostic performance of focal nodular hyperplasia and hepatocellular adenoma. Ultrasound Med Biol 41:944-951

76. Zarzour JG, Porter KK, Tchelepi H, Robbin ML (2018) Contrastenhanced ultrasound of benign liver lesions. Abdom Radiol 43: $848-860$

77. Dietrich CF, Schuessler G, Trojan J et al (2005) Differentiation of focal nodular hyperplasia and hepatocellular adenoma by contrastenhanced ultrasound. Br J Radiol 78:704-707
78. Hamer OW, Aguirre DA, Casola G et al (2006) Fatty liver: imaging patterns and pitfalls. Radiographics 26:1637-1653

79. Valls C, Iannacconne R, Alba E et al (2006) Fat in the liver: diagnosis and characterization. Eur Radiol 16:2292-2308

80. Liu LP, Dong BW, Yu XL et al (2008) Evaluation of focal fatty infiltration of the liver using color Doppler and contrast-enhanced sonography. J Clin Ultrasound 36:560-566

81. Dachman AH, Ros PR, Goodman ZD et al (1987) Nodular regenerative hyperplasia of the liver: clinical and radiologic observations. AJR Am J Roentgenol 148:717-722

82. von Herbay A, Westendorff J, Gregor M (2010) Contrast-enhanced ultrasound with SonoVue: differentiation between benign and malignant focal liver lesions in 317 patients. J Clin Ultrasound 38:1-9

83. Wu M, Li L, Wang J et al (2018) Contrast-enhanced US for characterization of focal liver lesions: a comprehensive meta-analysis. Eur Radiol 28:2077-2088

84. Liu GJ, Lu MD, Xie XY et al (2008) Real-time contrast-enhanced ultrasound imaging of infected focal liver lesions. J Ultrasound Med 27:657-666

85. Popescu A, Sporea I, Sirli R et al (2015) Does contrast enhanced ultrasound improve the management of liver abscesses? A single centre experience. Med Ultrason 17:451-455

86. Baheti AD, Chapman T, Rudzinski E et al (2018) Diagnosis, histopathologic correlation and management of hepatoblastoma: what the radiologist needs to know. Clin Imaging 52:273-279

87. Walther A, Tiao G (2013) Approach to pediatric hepatocellular carcinoma. Clin Liver Dis 2:219-222

88. Czauderna P, Mackinlay G, Perilongo G et al (2002) Hepatocellular carcinoma in children: results of the first prospective study of the International Society of Pediatric Oncology Group. J Clin Oncol 20: 2798-2804

89. Zhou S, Venkatramani R, Gupta S et al (2017) Hepatocellular malignant neoplasm, NOS: a clinicopathological study of 11 cases from a single institution. Histopathology 71:813-822

90. Prokurat A, Kluge P, Kosciesza A et al (2002) Transitional liver cell tumors (TLCT) in older children and adolescents: a novel group of aggressive hepatic tumors expressing beta-catenin. Med Pediatr Oncol 39:510-518

91. Katzenstein HM, Krailo MD, Malogolowkin MH et al (2003) Fibrolamellar hepatocellular carcinoma in children and adolescents. Cancer 97:2006-2012

92. Mandry D, Bressenot A, Galloy MA et al (2007) Contrastenhanced ultrasound in fibro-lamellar hepatocellular carcinoma: a case report. Eur J Ultrasound 28:547-552

93. Murphy-Lavallee J, Jang HJ, Kim TK et al (2007) Are metastases really hypovascular in the arterial phase? The perspective based on contrast-enhanced ultrasonography. J Ultrasound Med 26:15451556

94. Danila M, Popescu A, Sirli R et al (2010) Contrast enhanced ultrasound (CEUS) in the evaluation of liver metastases. Med Ultrason 12:233-237

95. Corvino A, Catalano O, Corvino F et al (2017) Diagnostic performance and confidence of contrast-enhanced ultrasound in the differential diagnosis of cystic and cysticlike liver lesions. AJR Am J Roentgenol 209:W119-W127

96. Trenker C, Kunsch S, Michl P et al (2014) Contrast-enhanced ultrasound (CEUS) in hepatic lymphoma: retrospective evaluation in 38 cases. Ultraschall Med 35:142-148

97. Strobel D, Seitz K, Blank W et al (2008) Contrast-enhanced ultrasound for the characterization of focal liver lesions - diagnostic accuracy in clinical practice (DEGUM multicenter trial). Ultraschall Med 29:499-505

98. Strobel D, Bernatik T, Blank W et al (2011) Diagnostic accuracy of CEUS in the differential diagnosis of small $(</=20 \mathrm{~mm})$ and subcentimetric $(</=10 \mathrm{~mm})$ focal liver lesions in comparison with 
histology. Results of the DEGUM multicenter trial. Ultraschall Med 32:593-597

99. Strobel D, Seitz K, Blank W et al (2009) Tumor-specific vascularization pattern of liver metastasis, hepatocellular carcinoma, hemangioma and focal nodular hyperplasia in the differential diagnosis of 1,349 liver lesions in contrast-enhanced ultrasound (CEUS). Ultraschall Med 30:376-382

100. Wu W, Chen MH, Yin SS et al (2006) The role of contrastenhanced sonography of focal liver lesions before percutaneous biopsy. AJR Am J Roentgenol 187:752-761

101. Pei XQ, Liu LZ, Liu M et al (2012) Contrast-enhanced ultrasonography of hepatocellular carcinoma: correlation between quantitative parameters and histological grading. Br J Radiol 85:e740 e747

102. Rennert J, Georgieva M, Schreyer AG et al (2011) Image fusion of contrast enhanced ultrasound (CEUS) with computed tomography
(CT) or magnetic resonance imaging (MRI) using volume navigation for detection, characterization and planning of therapeutic interventions of liver tumors. Clin Hemorheol Microcirc 49:67-81

103. Wang ZL, Tang J, Weskott HP et al (2008) Undetermined focal liver lesions on gray-scale ultrasound in patients with fatty liver: characterization with contrast-enhanced ultrasound. J Gastroenterol Hepatol 23:1511-1519

104. Soye JA, Mullan CP, Porter S et al (2007) The use of contrastenhanced ultrasound in the characterisation of focal liver lesions. Ulster Med J 76:22-25

Publisher's note Springer Nature remains neutral with regard to jurisdictional claims in published maps and institutional affiliations. 